\title{
Excess risk of lymphomas, leukemia and myeloma in patients with rheumatoid arthritis*
}

\author{
H A ISOMÄKI, T HAKULINEN AND U JOUTSENLAHTI \\ From the Rheumatism Foundation Hospital, 18120 Heinola 12; the Finnish Cancer Registry, 00170 \\ Helsinki 17; and the Social Insurance Institution of Finland, 00250 Helsinki 25, Finland
}

SUMMARY The incidence of malignant neoplasms among 11483 male and 34618 female individuals with rheumatoid arthritis was studied using two separate nationwide data registers covering the whole Finnish population: the Social Insurance Institution's Population Data Register, which includes information on medication for certain chronic diseases, and the Finnish Cancer Registry, with data on all cancer patients diagnosed in Finland. The follow-up comprised a total of 213911 person years. The total incidence of all malignant neoplasms was higher in males and on the level expected in females. The expected number of cases of leukemia, lymphomas, Hodgkin's disease and myeloma in both sexes was 59.6 as compared with the 130 cases observed. This difference is statistically highly significant $(p<0.001)$. The incidence of cancer of the respiratory organs was higher in males, and the incidence of cancer of the rectum and stomach lower than expected in rheumatoid females.

Conflicting evidence has been presented on the risk of malignant neoplasms in patients with rheumatoid arthritis (RA). Moesman ${ }^{151}$ found cancer to be twice as common in rheumatoid patients as in the general population. On the other hand, the proportion of malignant neoplasms as a cause of death in patients with rheumatoid arthritis was lower than that in controls matched for sex and age. ${ }^{102}$ Cancer was underrepresented in two autopsied series of rheumatoid arthritis. ${ }^{13}{ }^{156}$ Lewis et al ${ }^{126}$ found that cancer was less common in hospitalized RA patients than in patients with hypertension.

Special attention has been paid to the simultaneous occurrence of lymphoproliferative neoplasms and inflammatory rheumatic diseases such as RA. ${ }^{26} 29149234$ Oleinick $^{161}$ studied the literature in English published up to December 1965 . He collected a series of 951 RA patients with 9346 person

\footnotetext{
*Reprinted from J Chron Dis 1978; 31: 691-6.
}

years at risk from published case reports. No support was found for the hypothesis that there is an increased risk of leukemia or lymphoma in RA patients. Miller ${ }^{149}$ found the same prevalence of RA in patients with solid tumors $(0.42 \%)$ or lymphoproliferative neoplasms $(0.38 \%)$ as in the general American population $(0.38 \%)$.

It is possible that the immunological abnormality in RA patients increases the risk of contracting leukemia, lymphoma, or myeloma. The case reports cannot, however, resolve this question. The potential significance of this hypothesis in an understanding of the pathogenesis of these malignancies warrants further investigation. ${ }^{161}$

In this study the incidence of cancer in a large series of patients with rheumatoid arthritis was evaluated.

\section{Patients and methods}

The incidence of malignant neoplasms in rheumatoid arthritis patients was studied by making use of two computerized nationwide data registers, the Social Insurance Institution's Population Data Register and the Finnish Cancer Registry.

The Social Insurance Institution's Population Data Register has included information since 1965 on patients with chronic diseases entitling them to reimbursable medicines. One such disease is rheumatoid arthritis. The category 'rheumatoid arthritis' in this register also includes systemic connective tissue diseases (before 1970) and ankylosing spondylitis (from 1970 onwards). In 1974, subjects with ankylosing spondylitis accounted for $2 \cdot 2 \%$ of all patients and those with systemic connective tissue diseases for $1.7 \%$ of all patients in the register. ${ }^{170}$

The Finnish Cancer Registry ${ }^{213}$ was started in 1952, and according to established health service practice, every cancer case is reported to this registry. Reporting has been obligatory since 1961 . The registry receives information from multiple sources: from hospitals (at various stages of the disease), from practitioners, and from pathological laboratories. Moreover, the registry makes an annual screening of 
all death certificates issued in the country, and thus is informed of the death of cancer patients from both cancerous and non-cancerous causes. On average, five notifications are received per case.

The patients entitled to fully reimbursable medication because of RA during the period 1967-1973 were retrieved from the Social Insurance Institution's Population Data Register. A total of 11483 male and 34618 female RA patients were identified.

This RA patient series was matched against the Finnish Cancer Registry. The series was followed up for new cancer cases on or after 1 January 1967, from

TABLE 1 All malignant neoplasms in males by age

\begin{tabular}{lrrrr}
\hline Age & $\begin{array}{l}\text { Number of } \\
\text { rheumatoid } \\
\text { patients }\end{array}$ & $\begin{array}{l}\text { Person years } \\
\text { at risk }\end{array}$ & Observed & Expected \\
\hline $0-4$ & 34 & $38 \cdot 1$ & 0 & $0 \cdot 0$ \\
$5-9$ & 94 & $234 \cdot 3$ & 1 & $0 \cdot 0$ \\
$10-14$ & 107 & $384 \cdot 5$ & 0 & $0 \cdot 0$ \\
$15-19$ & 151 & $575 \cdot 8$ & 0 & $0 \cdot 1$ \\
$20-24$ & 340 & $1061 \cdot 4$ & 1 & $0 \cdot 2$ \\
$25-29$ & 457 & $1649 \cdot 8$ & 0 & $0 \cdot 4$ \\
$30-34$ & 611 & $2201 \cdot 4$ & 1 & $0 \cdot 8$ \\
$35-39$ & 772 & $2948 \cdot 6$ & 2 & $1 \cdot 8$ \\
$40-44$ & 1063 & $3920 \cdot 3$ & 7 & $4 \cdot 3$ \\
$45-49$ & 1181 & $4997 \cdot 8$ & 11 & $10 \cdot 1$ \\
$50-54$ & 1397 & $5659 \cdot 7$ & 24 & $21 \cdot 7$ \\
$55-59$ & 1760 & $7301 \cdot 4$ & 60 & $48 \cdot 7$ \\
$60-64$ & 1691 & $7855 \cdot 0$ & 95 & $85 \cdot 2$ \\
$65-69$ & 998 & $5674 \cdot 3$ & 99 & $83 \cdot 4$ \\
$70-74$ & 515 & $2883 \cdot 3$ & 50 & $56 \cdot 2$ \\
$75-79$ & 222 & $1262 \cdot 2$ & 42 & $29 \cdot 0$ \\
$80-84$ & 78 & $408 \cdot 4$ & 14 & $10 \cdot 1$ \\
$85-$ & 12 & $74 \cdot 8$ & 0 & $2 \cdot 1$ \\
All & 11483 & $49131 \cdot 0$ & 407 & $354 \cdot 1$ \\
\hline
\end{tabular}

The approximated Poisson confidence limits for the observed number of cases: $95 \%, 368 \cdot 4-448 \cdot 6 ; 99 \%, 356 \cdot 7-461 \cdot 7$.

TABLE 2 Occurrence of different malignant neoplasms in rheumatoid males

\begin{tabular}{|c|c|c|c|}
\hline Primary site & Observed & Expected & $\begin{array}{l}\text { Statistical } \\
\text { significance }\end{array}$ \\
\hline Lip, oral cavity & 12 & $13 \cdot 27$ & NS \\
\hline Esophagus & 5 & $7 \cdot 45$ & NS \\
\hline Stomach & 51 & $53 \cdot 55$ & NS \\
\hline Colon & 11 & $9 \cdot 88$ & NS \\
\hline Rectum & 7 & $10 \cdot 99$ & NS \\
\hline Liver, primary & 5 & $3 \cdot 25$ & NS \\
\hline Gallbladder & 2 & $2 \cdot 16$ & NS \\
\hline Pancreas & 16 & $14 \cdot 35$ & NS \\
\hline Respiratory organs & 171 & $132 \cdot 75$ & $\mathrm{p}<0.01$ \\
\hline Melanoma of the skin & 4 & $3 \cdot 20$ & NS \\
\hline \multicolumn{4}{|l|}{ Skin other, excluding } \\
\hline basalioma & 8 & 665 & NS \\
\hline Prostate & 30 & 30.43 & NS \\
\hline Urinary organs & 14 & 2088 & NS \\
\hline Brain & 9 & $5 \cdot 27$ & NS \\
\hline Thyroid gland & 2 & 1.44 & NS \\
\hline Hodgkin's disease & 5 & $2 \cdot 28$ & NS \\
\hline Lymphomas & 13 & $4 \cdot 84$ & $p<0.01$ \\
\hline Myeloma & 7 & $3 \cdot 26$ & $p<0.05$ \\
\hline Leukemia & 18 & $7 \cdot 10$ & $p<0.01$ \\
\hline \multicolumn{4}{|l|}{ Other and unspecified } \\
\hline sites & 17 & $21 \cdot 11$ & NS \\
\hline All & 407 & $354 \cdot 11$ & $\mathrm{p}<0.01$ \\
\hline
\end{tabular}

TABLE 3 All malignant neoplasms in females by age

\begin{tabular}{lcrrr}
\hline Age & $\begin{array}{l}\text { Number of } \\
\text { rheumatoid } \\
\text { patients }\end{array}$ & $\begin{array}{l}\text { Person years } \\
\text { at risk }\end{array}$ & Observed & Expected \\
\hline $0-4$ & 97 & $130 \cdot 3$ & 0 & $0 \cdot 0$ \\
$5-9$ & 157 & $599 \cdot 3$ & 0 & $0 \cdot 1$ \\
$10-14$ & 205 & $743 \cdot 8$ & 1 & $0 \cdot 1$ \\
$15-19$ & 460 & $1336 \cdot 5$ & 0 & $0 \cdot 2$ \\
$20-24$ & 751 & $2861 \cdot 4$ & 1 & $0 \cdot 6$ \\
$25-29$ & 1079 & $4060 \cdot 4$ & 1 & $1 \cdot 2$ \\
$30-34$ & 1467 & $6085 \cdot 8$ & 4 & $3 \cdot 4$ \\
$35-39$ & 2007 & $8156 \cdot 8$ & 9 & $8 \cdot 4$ \\
$40-44$ & 2673 & $11382 \cdot 0$ & 16 & $18 \cdot 8$ \\
$45-49$ & 3481 & $15028 \cdot 9$ & 43 & $40 \cdot 7$ \\
$50-54$ & 4570 & $19083 \cdot 4$ & 58 & $64 \cdot 6$ \\
$55-59$ & 5774 & $25843 \cdot 3$ & 94 & $105 \cdot 8$ \\
$60-64$ & 5130 & $27535 \cdot 3$ & 153 & $151 \cdot 0$ \\
$65-69$ & 3260 & $20631 \cdot 5$ & 163 & $147 \cdot 5$ \\
$70-74$ & 2065 & $12123 \cdot 6$ & 114 & $116 \cdot 5$ \\
$75-79$ & 1075 & $6364 \cdot 5$ & 89 & $79 \cdot 4$ \\
$80-84$ & 290 & $2248 \cdot 3$ & 37 & $35 \cdot 2$ \\
$85-$ & 77 & $565 \cdot 5$ & 12 & $10 \cdot 5$ \\
All & 34618 & $164780 \cdot 4$ & 795 & $783 \cdot 8$ \\
\hline
\end{tabular}

The approximated Poisson confidence limits for the observed number of cases: $95 \%, 740 \cdot 7-852 \cdot 3 ; 99 \%, 724 \cdot 0-870 \cdot 3$.

TABLE 4 Occurrence of different malignant neoplasms in rheumatoid females

\begin{tabular}{lrrl}
\hline Primary site & Observed & Expected & $\begin{array}{l}\text { Statistical } \\
\text { significance }\end{array}$ \\
\hline Lip, oral cavity & 10 & $13 \cdot 32$ & NS \\
Esophagus & 21 & $20 \cdot 38$ & NS \\
Stomach & 80 & $99 \cdot 76$ & p<0.05 \\
Colon & 33 & $39 \cdot 26$ & NS \\
Rectum & 20 & $34 \cdot 47$ & p $<0.05$ \\
Liver & 6 & $5 \cdot 85$ & NS \\
Gallbladder & 10 & $14 \cdot 32$ & NS \\
Pancreas & 32 & $30 \cdot 00$ & NS \\
Respiratory organs & 34 & $30 \cdot 98$ & NS \\
Melanoma of the skin & 17 & $10 \cdot 82$ & NS \\
Skin other, excluding & & & \\
$\quad$ basalioma & 18 & $16 \cdot 58$ & NS \\
Breast & 153 & $148 \cdot 67$ & NS \\
Cervix uteri, excluding in situ & 56 & $53 \cdot 76$ & NS \\
Corpus uteri & 50 & $50 \cdot 01$ & NS \\
Ovary & 39 & $46 \cdot 83$ & NS \\
Other genital organs & 11 & $10 \cdot 82$ & NS \\
Urinary organs & 31 & $27 \cdot 79$ & NS \\
Brain & 20 & $15 \cdot 80$ & NS \\
Thyroid gland & 7 & $10 \cdot 92$ & NS \\
Hodgkin's disease & 14 & $4 \cdot 54$ & p $<0 \cdot 001$ \\
Lymphomas & 25 & $9 \cdot 34$ & p<0.001 \\
Myeloma & 21 & $9 \cdot 49$ & p<0.001 \\
Leukemia & 27 & $18 \cdot 74$ & NS \\
Other and unspecified sites & 60 & $61 \cdot 33$ & NS \\
All & 795 & $783 \cdot 78$ & NS \\
\hline
\end{tabular}

the time at which RA medication was prescribed until 31 December 1973 , or the death of the patient (a total of 213911 person years). Malignant diseases contracted before the diagnosis of RA were excluded.

The numbers of various types of neoplasms in both sexes were compared with those expected on the basis of the national cancer morbidity figures for the years $1966-1970 .{ }^{213}$ The significance of the differences was tested on the assumption that the observed number of cases followed a Poisson distribution. ${ }^{57}$ 


\section{Results}

A total of 407 neoplasms were observed in males, the expected number of cases being $354 \cdot 1$. This difference is statistically significant $(\mathrm{p}<0.01$, table 1$)$. The incidence of leukemia, lymphomas, myeloma, and cancer of the respiratory organs was significantly higher in rheumatoid patients than in the general male population (table 2 ).

In females, the incidence of malignant neoplasms was approximately equal to that expected (table 3 ). An excess of leukemia was observed, but the difference was not statistically significant. The incidence of lymphomas, myeloma and Hodgkin's disease was significantly higher in females too, while the incidence of cancer of the stomach and rectum was lower than expected (table 4).

The expected number of all cancers of the lymphatic system (leukemia, lymphomas, Hodgkin's disease, and myeloma) in both sexes was 59.6 compared with the 130 cases observed. This difference is statistically highly significant $(\mathrm{p}<0 \cdot 001)$.

\section{Discussion}

Both data registers used in this study cover the whole Finnish population. This is one major advantage of a small population ( 4.7 million). In addition, it is possible to avoid the problems facing investigators who have used hospital registers on tumors. When a study is based on hospital patient registers, it is always possible that some rheumatoid patients have malignancies that have been treated at other institutions, and the frequency of malignant neoplasms therefore seems low.

It is probable that the drug user data of the Social Insurance Institution's Population Data Register do not include all Finnish RA patients. According to this register, the prevalence of RA among the whole population in 1971 was $0.3 \%$ in males and $1.0 \%$ in females. These figures are low compared with the prevalence of RA obtained in epidemiological studies $^{148}$ which, however, usually only apply to prevalence in adult populations. On the other hand, the Finnish Cancer Registry includes practically all diagnosed cancer cases in the country. ${ }^{213}$

Cancer has been reported to be more common among patients with systemic lupus erythematosus than among, for example, those with RA and hypertension $^{126}$ or among the general population. ${ }^{29}$ The prevalence of all systemic connective tissue diseases, including SLE, in this population was only $1.7 \%$. It is probable that this does not significantly change the incidence of cancer in the total series. Moreover, no cancers were found among the causes of death of 30 SLE patients in the series of Feng $\mathrm{et} \mathrm{al}^{66}$

Many malignant neoplasms can cause rheumatic manifestations. This is especially true in children, in whom the clinical picture may suggest, e.g. juvenile rheumatoid arthritis. ${ }^{26}$ Multiple myeloma may confusingly resemble RA. ${ }^{234}$ Carcinoma polyarthritis is sometimes clinically indistinguishable from RA ${ }^{26}$ If these rheumatic manifestations preceded the overt appearance of malignancy, the patient may have been registered first as RA. Such cases are, however, rare and probably have no significant influence on the results.

In general, the incidence of epithelial cancers was as expected. The higher than expected incidence of cancer of the respiratory organs in males and the lower than expected incidence of cancer of the rectum and stomach in females may be due to chance. However, Bradley et al $^{11}$ found an association between rheumatoid factor positivity and lung cancer in a British population.

The excess risk of lymphomas, leukaemia, and myeloma in patients with RA seems indisputable. There has been discussion on whether or not continuous immunological stimulation in RA causes pron liferation and malignant transformation of somes clones of immunologically competent cells. ${ }^{23}$ Hyperplasia of the lymphoid system is one of the characteristics of RA, and plasmocytosis is frequently seen in this disease. Miller ${ }^{149}$ discusses the theories on the etiologic relationship between immune diseases and malignant lymphomas. In his series of 17 patients, the onset of both processes occurred simultaneously in nine. He therefore concludes that the patients are susceptible to both diseases.

The excess risk of leukemia among RA patients was greater for males than for females. The series includes male patients with ankylosing spondylitis. This disease is strongly associated with HL-A antigen B27. Lawler $e t$ al ${ }^{121}$ found an elevated frequency of this antigen in patients with lymphoblastic leukemia. It remains to be determined whether more cases of leukemia have accumulated among patients with ankylosing spondylitis than among rheumatoids.

The low proportion of cancer deaths in rheumatoid patients $^{13102} 152$ does not seem to be due to a low morbidity in cancer. Infections, cardiovascular diseases and renal diseases are more often the cause of death in rheumatoid than in non-rheumatoid subjects resulting in a lower than expected proportion of deaths due to cancer. ${ }^{33}{ }^{102}{ }^{152}$ In addition, the definition of the cause of death of an individual patient is always a matter of debate. 